\title{
Arte e Percepção: as contribuições de Simondon para pensar o alcance político da experimentação sensível
}

\section{Art and Perception: Simondon's contributions for political range interpretation of sensible experimentation}

\begin{abstract}
Resumo:
No presente artigo buscamos mostrar a importância do pensamento de Gilbert Simondon, mais especificamente de sua forma de colocação do problema da percepção, para o campo da arte. A contribuição de Gilbert Simondon se faz relevante pois permite pensar uma abordagem do acontecimento artístico que escapa das armadilhas de um pensamento dicotômico segundo o qual haveria sempre uma escolha a realizar: ou falamos do aspecto formal e objetivo da obra, abrindo mão da dimensão da experiência e das relações da arte com outros processos vitais; ou nos restringimos aos significados e efeitos da obra, o que nos colocaria em sintonia com uma abordagem subjetivista que remete às intenções ou motivações do artista e às expectativas e preferências do espectador. A partir de uma discussão da leitura inventiva que Simondon realiza da Psicologia da Gestalt e articulando-a com o trabalho de autores como G. Deleuze e F. Guattari, tomando nesse sentido os conceitos de campo, metaestabilidade, forma, informação e modulação como fio condutor, mostraremos que é possível pensar em um mesmo movimento a consistência impessoal da obra e sua potência de novas atualizações ou individuações. Isso é importante pois aponta para a mobilização de uma dimensão não recognitiva da percepção na experiência com a arte. A obra se coloca então como dispositivo de experimentação. Analisaremos, finalmente, como esse caráter de experimentação sensível confere à experiência com a arte uma dimensão de produção de subjetividade e consequentemente, seu alcance político.

Palavras-chave: Arte. Percepção. Experimentação. Produção de subjetividade. Política.
\end{abstract}

\section{Abstract:}

In the following article we intend to show the importance of Gilbert Simondon's work, more specifically his way of placing the problem of perception, for art studies. Simondon's contribution acquires relevance in the sense that it allows an approach of the artistic phenomenon that escapes from the traps of a dichotomous way of thinking which states that there would always be a choice to be made: either we talk about the formal and objective aspect of the work, giving up the dimension of the experience and the art's relationships with other vital processes; or we restrain ourselves to the significances and effects of the work of art, wich would put us in synch with a subjective view, one that refers to the artist's intentions or motivations, and to the viewer's expectations and preferences. Starting with a discussion on the ingenious reading that Simondon makes of the Gestalt's Psychology, and articulating it with the work of authors such as G. Deleuze and F. Guattari - and, in this sense, taking concepts such as field, metastability, form, information and modulation as guideline - we expect to show that it is possible to conceive, in a single movement, the impersonal consistency of the work of art and its potential for new actualizations or individuations. This is important in the sense that it points to a mobilization of a non recognitive dimension of perception within the experience with art. The work of art operates then as an experimentational device. Finally, we'll analyse how this character of sensible experimentation gives the experience with art its dimension of production of subjectivity and, therefore, its political range. Keywords: Art. Perception. Experimentation. Production of subjectivity. Politics.

FERRAZ, Gustavo Cruz. Arte e percepção: as contribuições de Simondon para pensar o alcance político da experimentação sensível. Informática na Educação: teoria \& prática, Porto Alegre, v. 15, n. 1, p. 115-129, jan./jun. 2012.

\section{Gustavo Cruz Ferraz}

Faculdade Salesiana Maria Auxiliadora

sse artigo parte da idéia de que há na obra de Gilbert Simondon elementos de grande importância na compreensão não só da experiência com a arte, mas também do alcance político dessa experiência. Tal afirmação pode parecer excessiva tendo em vista que nem a arte, nem a política são temas centrais na obra de Simondon. No entanto, o caminho que iremos percorrer aqui, e que dada a complexidade da obra de Simondon assim como das questões envolvendo arte e política não tem qualquer pretensão de esgotar o tema, buscará apontar em que direção essa relação pode ser construída. A linha sob a qual caminharemos e que marcará a convergência dessas questões é a percepção. Analisamos, privilegiadamente, a questão do encontro com a obra e seus efeitos, tendo por fim escapar de duas armadilhas. A primeira que estabelece uma dicotomia entre, por um lado, a dimensão formal e objetiva da obra e, por outro, a dimensão significativa ou de experiência com a obra. Nesta perspectiva dicotômica tudo se passa como se houvesse uma escolha a realizar: ou se assume um ponto de vista formalista, de uma expertise no qual se trata do as- 
pecto formal e objetivo da obra, abrindo mão da dimensão da experiência e das relações da arte com outros processos vitais; ou nos restringimos aos significados e efeitos da obra, o que nos colocaria em sintonia com uma abordagem subjetivista que remete necessariamente às intenções ou motivações do artista e às expectativas e preferências do espectador. A segunda diz respeito à idéia de que apenas uma arte 'engajada' seria passível de produzir efeitos políticos. A nosso ver o pensamento de Simondon, em articulação com intercessores diversos como a psicologia da Gestalt e autores como Gilles Deleuze e Félix Guattari, nos oferece uma via para que se possa escapar dessas armadilhas, tratando da experiência com a arte de forma a fazer justiça à singularidade desta experiência e lhe conferindo seu alcance político. Nesse sentido não se trata de um trabalho sobre a obra de Simondon, mas sim uma tentativa de trabalhar uma questão a partir de alguns de seus conceitos.

\section{A percepção como fenômeno de campo: contribuições e limites das teses gestaltistas}

É notória a contribuição da psicologia da Gestalt, que tem nos trabalhos de Max Wertheimer, Kurt Koffka e Wolfgang Köhler sua expressão mais acabada, aos estudos da percepção. Essa contribuição, que extravasa o domínio da psicologia como veremos logo adiante, se deve à profunda transformação operada por estes trabalhos no estatuto da percepção. Esta não é mais considerada o terreno da impressão passiva de dados elementares que seriam organizados subjetivamente. O plano da percepção já possui ele próprio uma ordem. A sensação, como um dado elementar bruto e cujas propriedades derivariam exclusivamente do estímulo físico local correspondente, não é um momento inicial da percepção, mas uma ficção construída a posteriori. Percebemos mais do que aquilo que se imprime na retina de nossos olhos (ou de forma mais geral, em nossas terminações periféricas). Percebemos relações, direções, movimentos, tensões. A profunda cisão entre o caos sensível e a ordem superior intelectual, advinda de uma longa tradição filosófica, ganha novos contornos. Todos estes componentes 'invisíveis' que fazem parte de nossa experiência eram classicamente atribuídos a uma atividade subjetiva superior e exterior ao domínio da percepção. Será então a partir das teses gestaltistas que estas fronteiras serão redesenhadas, de forma que nem todo 'invisível' seja da ordem do inteligível. Segundo suas teses, nossa experiência perceptiva primeira não é um caos, mas uma totalidade organizada. A percepção é a apreensão da configuração de um campo perceptivo, cuja estrutura mínima é a distinção figura/fundo. Uma unidade se destaca de um fundo e sua organização não deriva, fundamentalmente, de nossos conhecimentos prévios. A segregação das unidades perceptivas é anterior ao reconhecimento das formas e se coloca como condição do próprio reconhecimento. Desta forma não é preciso saber o que é um livro, por exemplo, para que se possa ver que 'algo' se destaca enquanto unidade no campo visual.

Segundo Simondon (1989, 2005, 2006) a grande novidade introduzida pela Teoria da Gestalt é precisamente abrir caminho para que se possa pensar a forma, ou estrutura, como contemporânea aos seus elementos. Em seu Cours Sur La perception Simondon (2006) ressalta que contrariamente ao que aprendemos habitualmente a teoria gestaltista da percepção não deve ser entendida como molar nem como molecular, já que o todo e as partes estão em constante inter-relação e se definem mutuamente.

A Psicologia da Gestalt renova a noção de forma 
e faz em certa medida a síntese da forma arquetípica platônica e da forma hilemórfica aristotélica graças à uma noção explicativa e exemplar, tirada das ciências da natureza: o campo ${ }^{1}$ (SIMONDON, 1989, p. 36).

A noção de campo desempenha aqui papel fundamental pois é a partir dela que se pode pensar "uma reciprocidade de status ontológicos e de modalidades operatórias entre o todo e o elemento" (SIMONDON, 1989, p. 44). Simondon chega a afirmar que "a definição do modo de interação característica do campo constitui uma verdadeira descoberta conceitual" (SIMONDON, 1989, p. 44). Um campo elétrico, eletromagnético ou gravitacional, consiste em um sistema distribuído de linhas de força que constituem uma configuração potencialmente ativa, ou seja, uma distribuição de energia. Em um campo, um elemento possui dois status e cumpre duas funções: na primeira, enquanto recebe a influência do campo, ele é submetido às suas forças, é um certo ponto do gradiente pelo qual pode-se representar a repartição do campo; na segunda, ele intervém no campo como ativo e criador, pois modifica as linhas de força deste e a repartição dos gradientes (SIMONDON, 1989). Assim, podemos dizer que uma vez que um corpo é colocado em um campo, não só este corpo sofrerá determinadas afecções e terá seu comportamento modificado, como também produzirá uma mudança no campo, já que em sua vizinhança a configuração será afetada de modo recíproco.

Afirmar que a percepção é um fenômeno de campo traz dois desdobramentos que serão de grande importância e que, podemos dizer, de certa forma respondem pela mobilização do interesse que as teses gestaltistas despertam no campo da arte. Interesse este que pode ser

1 Tradução nossa. Todas as traduções das obras não publicadas no Brasil são de nossa responsabilidade. atestado pela importância dos trabalhos teóricos sobre arte de Rudolf Arnheim nos EUA, os do crítico de arte Mário Pedrosa e da artista Fayga Ostrower no Brasil, assim como a explícita influência em movimentos artísticos como a poesia concretista² brasileira, por exemplo. Em primeiro lugar abre-se espaço para uma concepção altamente dinâmica da percepção, onde há uma constante interação parte-todo e onde se fazem presentes noções como densidade, tensão e força. Isto permite pensar a experiência perceptiva para além da impressão passiva de estímulos ou pura apreensão de formas, de forma que mesmo os espaços vazios são investidos de poder de ação. Fayga Ostrower dá uma descrição de como, por exemplo, isto opera na pintura:

Ao se introduzir no plano pictórico alguma marca visual, digamos, uma forma mais ou menos triangular, imediatamente se estabelece uma relação 'figura-fundo'. A figura triangular não apenas será percebida como elemento 'ativo', contrastando com o fundo 'passivo', como também a expansão espacial deixa de ser uniforme, diferenciando-se fisicamente ao se tornar mais densa e corpórea na área ocupada pelo triângulo. Mas as diferenças não param por aí. Em torno da figura triangular propaga-se um campo de tensões espaciais, que emanam desta figura e por ela também são delimitadas. Este campo é virtual e, portanto, invisível, mas ele é atuante, pois qualquer outra marca que for colocada em sua área será imediatamente afetada pelas tensões existentes. (OSTROWER, 1998, p. 94).

Um segundo ponto importante diz respeito ao fato de que, uma vez que a configuração do campo perceptivo está ligada ao grau de articulação dos padrões de estímulo e às condições de atualização do campo, a ordem que se faz presente no experiência perceptiva não deriva fundamentalmente do sujeito que per-

2 A psicologia da gestalt é nominalmente citada no 'Planopiloto da poesia concreta', de Augusto de Campos, Décio Pignatari e Haroldo de Campos, 1958. 
cebe. Isso será importante para os estudos no campo da arte, como ressalta Rudolf Arnheim, pois abre caminho para que se possa abordar a dimensão significativa e afetiva da experiência com a arte sem recair em abordagens psicologizantes que vêem na obra de arte apenas uma projeção de fatores subjetivos e da personalidade ${ }^{3}$. É nítida, e a nosso ver extremamente fértil, sua preocupação em buscar nas teorias gestaltistas recursos no sentido de se distanciar de certos estudos que "encaram a atividade artística principalmente como um instrumento de exploração da personalidade humana, como se entre arte e um borrão de tinta de Rorschach ou as respostas de um questionário houvesse pouca diferença" (ARNHEIM, 1991, p. 3).

Aqui, contudo, é importante nos determos mais cuidadosamente pois é sob o ponto em que são ancoradas as teses gestaltistas acerca do princípio que garante essa ordem imanente do campo perceptivo que incidem as limitações da leitura mais clássica dos trabaIhos dos gestaltistas e o interesse que assumem trabalhos como os de Arnheim e, mais especificamente, o de Simondon na superação dessas limitações.

Havia uma forte preocupação por parte dos primeiros teóricos gestaltistas em buscar, por um lado, construir uma teoria psicológica da percepção que fizesse justiça à experiência perceptiva tal como ela se dá, mas que, por outro lado, se afirmasse como estritamente científica de acordo com os padrões epistemológicos vigentes (início do século XX). Daí a importância de encontrar princípios explicativos que dessem conta da ordem percebida sem que fosse necessário supor quaisquer atividades reguladoras superiores. Nas palavras de Koffka:

3 Essa é de resto também uma discussão trazida por Mário Pedrosa. Cf Pedrosa, 1964, 1975. assim, aceitamos a ordem como uma característica real, mas não precisamos de qualquer agente especial para produzi-la, pois a ordem é uma consequência da organização e a organização o resultado de forças naturais. Desta maneira, nossa discussão tornou manifesto como a natureza produz ordem (KOFFKA, s/d, p. 186).

O conceito de isomorfismo desempenha aqui um importante papel, pois é a partir dele que é pensada a articulação com os processos de campo de ordem física e também fisiológica (sendo esta intermediária entre o mundo físico e o psicológico). Esta articulação é da ordem de uma correpondência estrutural. A objetividade da percepção residiria exatamente no rigor desta equivalência isomórfica entre a ordem percebida e a ordem física. O exemplo da auto-distribuição de cargas elétricas em corpos condutores isolados, é frequentemente utilizado para demonstrar processos físicos de auto-organização. Nestes processos é a tendência ao equilíbrio que rege a autoorganização, como postula o princípio geral de Le Châteler: "se uma alteração se produz num dos fatores que determinam uma condição de equilíbrio, o equilíbrio modifica-se de maneira tal que tende a anular o efeito dessa alteração" (GUILLAUME, 1966, p. 26). Assim, o sistema está em equilíbrio quando sua energia potencial é miníma, ou seja, quando suas forças compensam-se mutuamente de forma que nenhuma transformação ulterior seja possível e o estado final seja estável. A contrapartida psicológica do princípio de Le Châtelier é a chamada Lei da Boa Forma, expressa pela formulação: "a forma será tão boa quanto permitam as condições atuais" (KÖHLER, 1968, KOFFKA, $\mathrm{s} / \mathrm{d}$ ). Vemos aqui como o campo perceptivo, assim como os processos físicos de auto-organização, é estruturado a partir de sua tendência ao equilíbrio, ou seja, pela tendência de que a configuração resultante seja a mais estável de acordo com as condições dadas. A 
configuração do campo percebido, ou seja, a constituição de figura e fundo, a segregação de unidades perceptivas e suas respectivas localizações, enfim, todo o conjunto de articulações que delimitam grupos, subgrupos e suas inter-relações, respondem a um processo de equilibração que tende a alcançar um estado cujo grau de tensão é mínimo.

Vemos assim como a idéia de ordem fundada em processos de equilíbrio estacionário faz com que se passe da formulação de que o campo perceptivo é uma totalidade estruturada, para a afirmação de que percebemos formas simples e estáveis. A boa forma seria assim a forma simples, regular e simétrica. 0 aspecto problemático dessa constatação no que diz respeito a arte se faz evidente a partir da colocação de Ostrower:

$\mathrm{Na}$ arte, a noção de equilíbrio pressupõe, necessariamente, um estado altamente diferenciado. Sem isto, a noção da configuração expressiva, como um conjunto de componentes formais diferentes e diferenciados, ordenados de tal modo que se tornem equivalentes nesta totalidade formal, enfim, a noção de um equilíbrio não faria sentido. E nunca ele se tornaria expressivo (OSTROWER, 1998, p.186).

Como tivemos a oportunidade de mostrar em trabalhos anteriores (FERRAZ, 2010, FERRAZ; KASTRUP, 2010) é nesse sentido que se articulam e ganham relevânica para o campo da arte os trabalhos de Arnheim e Simondon, pois assinalam a relevância das idéias gestaltistas, mas apontam para a necessidade de complefixicar suas teses no que diz respeito ao equilíbrio e à boa forma ressaltando o caráter dinâmico da forma em sua pregnância e expressão. Não cabe aqui seguir todo o percurso argumentativo que mapeia os pontos de aproximação e afastamento entre estes autores, mas vale marcar que em sua análise, Arnheim guarda ainda a importância da questão do equilíbrio. No entanto segue no sentido de apontar a existência de duas faces indissociáveis da psicologia da Gestalt, que de resto correspondem a duas faces da própria percepção, que são: a face forma e a face campo de forças. Há assim uma leitura do gestaltismo presente nos trabalhos de Arnheim que reforça a colocação do problema da percepção a partir do campo de forças de onde emerge uma forma, numa luta entre o aumento e a redução da tensão. Algo que se tornava obscurecido pela sempre rápida passagem desta tese para a afirmação de que estas forças se anulam numa distribuição homogênea e estável. A boa forma não é, para Arnheim, necessariamente a forma mais simples, regular ou simétrica, mas sim a mais expressiva e a menos ambígua. Uma 'boa forma' não significa apenas uma forma mais simples, mas uma forma que cumpre sua função dentro de um padrão ótimo de regulação. Arnheim distingue os conceitos de boa forma (que em sua terminologia é tratada como lei da simplicidade) e pregnância. Em suas palavras

[...] esse aspecto estético da criação da forma, familiar a qualquer artista, mas ativa em toda percepção, caracteriza a forma perceptual como produto de um processo altamente dinâmico, no qual a tendência em direção ao aumento da tensão de articulação interage com a tendência contrária em direção ao equilíbrio em cada caso (ARNHEIM, 1986, p. 823).

A pregnância é contrária à ambigüidade, não à complexidade. Segundo Arnheim, por isso as obras de arte são frequentemente citadas na psicologia da Gestalt como exemplos eminentes de gestalts. Isto se dá não apenas pelo fato de as obras dependerem de uma organização estrutural perfeita, mas também porque ao mesmo tempo em que alcançam um alto grau de complexidade, nelas a forma perceptual é trabalhada no sentido da maior expressividade. É a expressividade da obra que garante que a reação do espectador seja 
distinta da mera recepção de informação, o que o leva a afirmar que "o que o artista cria com materiais físicos são experiências" (ARNHEIM, 1991, p. 10).

No trabalho de Arnheim há, contudo, ainda um espaço significativo concedido à questão do equilíbrio e da estabilidade das formas. Talvez isso se dê em função de sua preocupação com a composição da forma artística e seu esforço por estabelecer índices de qualidade estética para além de qualquer subjetivismo. Não se trata de assumir uma posição formalista ${ }^{4}$, mas de buscar princípios internos de consistência da obra, daí a valorização da questão da estabilidade das formas. É aqui, a nosso ver, que a contribuição de Simondon se torna mais fértil, pois escapar das armadiIhas do subjetivismo não implica a necessidade de minorar a possibilidade de diferenciação presente tanto no interior das obras quanto nas experiências que delas derivam (FERRAZ, 2010, FERRAZ; KASTRUP, 2010). É nesse sentido que o colocação do problema da percepção no contexto de sua teoria da individuação, e os conceitos de metaestabilidade, forma, informação e modulação que lhe são articulados ganham importância e seu justo alcance na presente discussão.

Como já vimos, a noção de campo é de grande importância para Simondon, pois permite pensar a percepção enquanto uma totalidade, um conjunto de relações dinâmicas no qual há correlação e reciprocidade entre parte e todo. No entanto, Simondon aponta como limite o fato de que, por trabalhar a partir de um paradigma físico por demais simplista (SIMONDON, 1989), os gestaltistas teriam sido levados à considerar a questão da ordem presente no campo perceptivo e o processo de tomada de forma a partir dos processos es-

4 Cf nesse sentido suas críticas às colocações do crítico Roger Fry em "A forma e o consumidor" (1997). tacionários de equilíbrio. Vale marcar que não só o postulado da Lei da Boa Forma nos levaria, segundo Simondon, a considerar como uma boa forma aquilo que é a degradação da forma, como também sua postulação como princípio é problemática, pois rege o processo de tomada de forma permanecendo exterior ao próprio processo. Situar a problemática da percepção no contexto da teoria da individuação é exatamente inverter esse estado de coisas. Como afirma Deleuze (2006) um dos pontos mais importantes da teoria da individuação em Simondon é o fato de que o indivíduo é tomado enquanto contemporâneo da individuação e a individuação é contemporânea ao princípio de individuação. 0 princípio deve ser verdadeiramente genético e não colocado antes da operação de individuar, ou seja, acima da própria individuação. Este tipo de inversão na forma de colocação dos problemas é característico do pensamento simondoniano, sendo, como assinalado, um dos pontos fundamentais de sua teoria da individuação. Esta teoria, como se sabe, não se reduz ao fenômeno da percepção e diz respeito aos mais variados planos de realidade, havendo individuações físicas, biológicas, psíquicas, coletivas, etc. Segundo Simondon é por partir dos indivíduos já constituídos e não dos processos de individuação que recaímos em modos de pensamento substancialistas e identitários perdendo de vista o caráter sempre movente e produtor de novidade do real. Pois há nesta forma de colocação do problema que parte do indivíduo e busca a condição de possibilidade de sua existência, sempre a suposição de que o princípio de individuação é anterior ao próprio processo. É dado aqui um privilégio ontológico ao indivíduo constituído, pois mesmo que se dêem transformações temporais estas são de caminho necessário. Há portanto o primado dos estados finais em detrimento dos processos. Se Simondon pro- 
põe então uma teoria da individuação é exatamente no sentido de inverter estes pólos. 0 indivíduo é contemporâneo de seu devir pois esse devir é o de sua própria individuação. "O devir não é devir do ser individuado, mas devir da individuação do ser" (SIMONDON, 1989, p. 24). Não cabe aqui seguir toda a filosofia da individuação de Simondon, mas vale apontar que é no interior deste quadro que se coloca a questão da percepção para Simondon, assim como suas considerações quanto à novidade e quanto aos limites das teses gestaltistas.

A segregação das unidades perceptivas, ou seja, a atualização do campo perceptivo, deve abarcar de fato a totalidade de suas condições,

[...] a teoria da Forma reduz a dois termos isto que é um conjunto de três termos independentes ou ao menos distintos: não é senão após a percepção que as tensões são efetivamente incorporadas ao campo psicológico e fazem parte de sua estrutura. Antes da percepção, antes da gênese da forma que é precisamente percepção, a relação de incompatibilidade entre o sujeito e o meio existe como um potencial apenas, da mesma maneira que as forças que existem na fase de metaestabilidade da solução supersaturada ou sólida em estado de sobrefusão, ou ainda na fase de metaestabilidade da relação entre uma espécie e seu meio. A percepção não é a apreensão de uma forma, mas a solução de um conflito, a descoberta de uma compatibilidade, a invenção de uma forma. Esta forma que é a percepção modifica não somente a relação do objeto e do sujeito, mas ainda a estrutura do objeto e aquela do sujeito" (SIMONDON, 1989, p. 76).

Assim como todo processo de individuação, a atualização de um campo perceptivo tem como condição de existência a metaestabilidade. Um sistema metaestável é um sistema tensionado, que guarda em si uma dissimetria ou uma diferença de potencial entre ordens de grandeza que inicialmente não se comunicam (SIMONDON, 1989, 2006). Falar em metaestabilidade implica portanto em falar em uma dimensão intensiva, uma repartição de limiares de ativação ou energia potencial. A metaestabilidade é de extrema importância pois permite pensar sistemas longe do equilíbrio sem que se recaia na instabilidade e na ausência completa de ordem. Como mostra o físico Ilya Prigogine (1988) por muito tempo a questão da ordem esteve atrelada aos processos de equilíbrio estacionário ${ }^{5}$. No entanto, este nos mostra que o estudo dos chamados sistemas longe do equilíbrio ganha cada vez mais importância em áreas diversas do conhecimento científico e vê-se que o antigo paradigma que sustentava a equivalência ordem/equilíbrio em oposição ao par desordem/não-equilíbrio é insuficiente e impreciso. Em suas palavras,

[...] classicamente associava-se a ordem ao equilíbrio [...] e a desordem ao não equilíbrio (caso da turbulência). Hoje sabemos que isso é inexato: a turbulência é um fenômeno altamente estruturado, em que milhões e milhões de partículas se perseguem num movimento extremamente coerente. Isto também é válido para muitos outros fenômenos como, por exemplo, os relógios químicos, que são reações oscilantes: podemos ver a solução tornar-se vermelha e depois azul, vermelha, azul, e assim por sucessivamente.... [...] Atualmente, as experiências de laboratório [...] mostram que, quando se depara com o domínio do não-equilíbrio, se estabelecem novas interações de longo alcance: o universo do nãoequilíbrio é um universo coerente. $E$ isto representa uma fato novo, que contradiz tudo quanto se pensava ainda há poucos anos (PRIGOGINE, 1988, p. 41).

O não-equilíbrio não é portanto a desordem, mas "o domínio por excelência da multiplicidade das soluções" (PRIGOGINE, 1988, p. 41). Dá-se a amplificação de flutuações que geram a constante possibilidade de novas estruturações. Como marca Prigogine isto é de extrema importância não só para a física mas

5 Daí podemos inclusive inferir o porquê do interesse dos gestaltistas e o forte acento que ganham estes processos em suas teses 
também para todos os saberes voltados para o domínio da vida.

Entrevemos aqui a ressonância desta discussão com as questões colocadas por Simondon, pois o conceito de metaestabilidade ganha importância precisamente porque permite pensar a estruturação sem que seja necessário supor o esgotamento dos potenciais. Sistemas metaestáveis, ou longe do equilíbrio como diria Prigogine, são sistemas estruturados mas que guardam em si potenciais de atividade. O processo de individuação é na verdade um processo de resolução parcial e relativa de um sistema metaestável (SIMONDON, 1989), desta forma a individuação engendra um indivíduo, mas mantém em si um potencial ativo, uma carga energética pré-individual. Simondon ressalta a dificuldade de uma definição conceitual precisa desta dimensão pré-individual, sugerindo que isto talvez seja fruto de uma longa tradição moldada por um pensamento substancialista. Mas faz questão de marcar sua a importância já que permite sair de um modo de pensamento que opera por meio de categorias opostas e exclusivas como uno $x$ múltitplo ou ainda contínuo $x$ descontínuo.

Segundo Simondon, o problema da segregação das unidades perceptivas traz à tona algo que os fundadores do gestaltismo haviam visto bem: nenhum processo de individuação é reservado a um único domínio de realidade, seja ele por exemplo físico ou psicológico. Assim, não há realidade individuada que não seja mista, ou na terminologia simondoniana, transdutiva, ou seja, que comporte em si uma defasagem em relação a si mesmo, um sistema em que se produz um estado metaestável (SIMONDON, 1989). No entanto, o recurso dos gestaltistas à lei da Boa Forma e ao isomorfismo impede que se pense mais profundamente a totalidade das relações e atravessamentos entre planos e ordens diversas de realidade. As colocações de Simondon acerca da metaestabilidade e do plano pré-individual são aqui de extrema importância. Retomando a passagem citada acima na qual Simondon afirmava que os gestaltistas não tomavam de fato a totalidade das condições envolvidas no processo de atualização do campo perceptivo, vemos que se ressalta o caráter vital da percepção assim como a relação sujeito-meio (poderíamos dizer ainda organismo-meio) enquanto sistema metaestável. Como bem ressalta Rennaud Barbaras em seu texto de apresentação do Cours sur La Perception, desde Bergson se sabe que a percepção não diz do conhecimento, mas da vida, e é por isso que deve ser tomada do ponto de vista de sua significação biológica tanto quanto de seu alcance informativo. Ela é descrita portanto como a modalidade originária da relação do vivo com seu meio, a forma pela qual ele entre primeiramente em contato com ele. O ponto mais importante no pensamento de Simondon é que esta relação vital comporta uma processualidade que não se resume a uma adaptação do organismo há um meio já dado. Vale repetir as palavras de Simondon "A percepção não é a apreensão de uma forma, mas a solução de um conflito, a descoberta de uma compatibilidade, a invenção de uma forma. Esta forma que é a percepção modifica não somente a relação do objeto e do sujeito, mas ainda a estrutura do objeto e aquela do sujeito" (SIMONDON, 1989, p. 76). A situação perceptiva implica uma compatibilização entre organismo-meio, mas essa compatibilização atravessa ordens heterogêneas e transforma tanto o organismo quanto o meio, multiplicando os eixos axiomáticos que compõem a relação organismo-meio.

Simondon sublinha então a necessidade de estabelecer uma distinção entre dois níveis de segregação das unidades perceptivas. Num primeiro nível a segregação se dá de acordo com o princípio de assimetria, implicando uma 
diferença de potencial que cria uma heterogeneidade no campo configurando polaridades afetivas. Apenas num segundo nível a lei da boa forma se aplica, produzindo um equilíbrio estável nos sub-conjuntos destacados. Para além de um conjunto de transformações convergentes na direção da estabilidade e do equilíbrio, há um momento em que a diferença de potencial alcança um grau limite, onde o sistema possui um grau máximo de ativação. Vê-se assim que o equilíbrio estável só surge quando o que ele chama de "problema perceptivo" já está resolvido. No entanto o que Simondon reforça é que o ponto chave para a justa compreensão do fenômeno perceptivo se encontra precisamente em sua face 'problemática', e não em sua face de problema já solucionado.

A questão da tomada de forma, ou de configuração do campo perceptivo, não se descola portanto da dimensão intensiva e pré-individual, na qual ordens de grandeza distintas fazem sistema por meio de uma diferença de potencial. É por essa via que Simondon buscará complementar a idéia de forma gestaltista a partir do conceito de informação ${ }^{6}$, que diz respeito ao processo de estruturação comportando essa dimensão intensiva e, portanto, relacional. Como ressalta Escóssia,

Tensão, intensidade e potencial de informação ou de forma. Qualquer que seja o termo utilizado nesse contexto conceitual, o significado é um só: concentração até o limite disruptivo; reunião de contrários em unidade; existência de um campo interior a esse esquema de informação; e ainda, dimensão que reúne aspectos ou dinamismos habitualmente incompatíveis entre eles (ESCÓSSIA, 2004, p. 73).

Nesse sentido Simondon se pergunta sobre a questão da Boa Forma:

6 Simondon faz questão aqui de marcar sua distância em relação às teorias tecnológicas da informação que equiparam o conceito de informação a um sinal, suporte, ou veículo de informação em uma mensagem.

\begin{abstract}
A boa forma não seria aquela que contém um campo de forma elevado, isto é, uma boa distinção, um bom isolamento entre os dois termos ou a pluralidade de termos que a constituem, e entretanto, entre eles, um campo intenso, isto é, um poder de produzir efeitos enérgicos se alguém ali introduz algo? (SIMONDON, 1989, p. 52).
\end{abstract}

Todo processo de tomada de forma envolve duas condições: a ação estruturante levada a cabo por um germe estrutural e uma energia contida pelo meio/matéria/domínio a ser informável. A boa forma, ou tensão de informação, é portanto aquela que mantém o nível energético do sistema, conservando seus potenciais e os compatibilizando. É a ligação significativa do uno e do múltiplo, estando assim 'próxima do paradoxo, próxima da contradição, não sendo contraditória em termos lógicos' (SIMONDON, 1989, p. 53). A tensão de informação é a propriedade que permite ao sistema estruturar um domínio e propagar-se através dele, ordenando-o. O processo de tomada de forma se desenrola portanto como transdução, ou modulação, uma operação na qual a ação estrurante de um germe estrutural avança sobre um domínio metaestável. Nas palavras de Simondon:

[...] esse tipo particular de relação que existe entre a tensão de informação do germe estrutural e o domínio informável, que possui uma energia potencial, faz da operação de tomada de forma uma modulação (SIMONDON, 1989, p. 54).

É importante destacar que Simondon não recusa, mas procura recuperar e complementar as noções gestaltistas de forma e pregnância. Na mesma direção sublinhada por Arnheim, afirma que a pregnância da forma não deve ser pensada a partir da estabilidade e da redução homogeneizante de tensão, mas sim pela capacidade de "atravessar, de animar e de estruturar um domínio variado, domínios cada vez mais variados e heterogê- 
neos" (SIMONDON, 1989, p. 53). A pregnância está intimamente ligada ao caráter intensivo e dinâmico da forma, e não à sua estabilidade. Diz respeito portanto ao grau de tensão de informação e sua potência de modulação, de estruturação de ordens diversas e domínios metaestáveis "Ela não é uma uma consequência da forma somente, mas também, e sobretudo, do alcance da solução que ela constitui para a problemática vital" (SIMONDON, 1989, p. 92).

\section{0 alcance político da experimentação sensível}

Até aqui realizamos um percurso no qual partimos de algumas questões ligadas a percepção, mais especificamente das teses gestaltistas. O interesse por estes trabalhos se deve por um lado, à importância concedida por Simondon a estes trabalhos, mais especificamente sua colocação do problema da percepção a partir do conceito de campo e; por outro lado, ao interesse crescente que esses trabalhos mobilizaram no campo da arte. Em um segundo momento, buscamos delinear algumas contribuições de Simondon que permitem escapar das limitações presentes nas teses gestaltistas, mais especificamente no que concerne ao modelo de redução de tensão e à estabilidade das formas. Cabe agora retomarmos algumas questões mais estreitamente ligadas à arte para conferirmos o justo alcance à questão que nos propomos discutir.

Pablo Picasso dizia com a mesma robusta, e apenas aparente, simplicidade de suas obras: "Para mim não há passado ou futuro na arte. Se uma obra de arte não pode viver sempre no presente ela não deve, de maneira nenhuma, ser considerada" (PICASSO, 2003, p. 216). É também a esta capacidade de "viver sempre no presente" que o poeta Paul Valéry se referia ao se perguntar, assombrado, como podem se manter vivos o interesse e a comoção diante de poemas cuja produção e recepção são separadas por séculos. Note-se que a discussão está para além do caráter "atual" de uma obra, pois devemos inverter a direção do pensamento habitual: trata-se de pensar a atualidade da obra a partir de sua potência (sua atualidade como potência), e não de explicar sua potência a partir de sua atualidade. Podemos dizer que se a arte sobrevive no tempo, é porque o tempo sobrevive nela.

É neste sentido que, a nosso ver, Paul Klee afirma: "A obra de arte [...] é em primeiro lugar gênese, não a apreendemos jamais como produto" (KLEE, 1964, p. 38). É interessante notar que mesmo em uma escala menor, no plano das relações que temos ou que mantemos com certas obras, algo deste gênero se manifesta. As grandes obras mantém viva sua força de afetação, que se manifesta seja por meio da viva impressão de que retomar o contato com elas implica sempre uma inocência reecontrada, seja por meio da recorrência de traços das mais variadas ordens, como personagens, sons, tons de cores, pequenas passagens, frases, ambientes, imagens soltas, que nos invadem ao longo da vida e que muitas vezes fazem despertar novas superfícies de contato com o mundo. Começamos a entrever aqui os pontos de contato que se esboçam com o que Simondon afirma acerca da boa forma, enquanto tensão de informação, e de seu caráter pregnante. A pregnância da forma artística é a permanência de uma metaestabilidade, da capacidade de "atravessar, de animar e de estruturar um domínio variado, domínios cada vez mais variados e heterogêneos" (SIMONDON, 1989, p. 53). Por isso G. Deleuze e F. Guattari podem dizer que a arte conserva, na verdade, 'é a única coisa no mundo que se conserva' (DELEUZE; GUATTARI, 1992, p. 213).

Nas palavras de José Gil (1996) 
A 'perenidade' da arte vem daí, do fato de as suas forças constituírem uma reserva 'eterna' de forças. A técnica do artista não visa de início produzir formas 'belas', 'sublimes', 'interessantes', 'saturadas', mas tratar de tal maneira os materiais que as formas nascentes contenham feixes de forças. As formas visíveis são apenas as teclas de um piano que o artista faz tocar a fim de por forças em movimento - movimento que, por seu turno, anima as formas de uma vida intensa (GIL, 1996, p. 301).

A especificidade da forma artística, assim como seu poder de ação, é sua potência continuamente moduladora. Nesse ponto o pensamento de Simondon se articula com os trabalhos de G. Deleuze e F. Guattari. Para estes aquilo que permite que falemos em arte no singular é a comunidade de um problema: a captura de forças. Em arte "não se trata de reproduzir ou inventar formas, mas de captar forças" (DELEUZE, 2007, p. 62). Esta formulação está presente em Lógica da Sensação, mas de alguma maneira atravessa todos os trabalhos de Deleuze, assim como aqueles com Guattari, voltados para a arte. Pode-se desdobrá-la sob diferentes aspectos, mas cabe apontar inicialmente que a ênfase não parece ser na dicotomia entre formas e forças.

Um dos pontos importantes da colocação da arte como captura de forças consiste precisamente na possibilidade de fazer fugir o modo de pensar dicotômico que opera, sob diferentes faces, a partir de pares de opostos mutuamente exclusivos. O que está em jogo é a perda do estatuto unificador, substancial e totalizante da forma. Estatuto este que a emancipa de todo vínculo com o plano movente e genético das forças. Se falamos em plano movente e genético, poderíamos dizer ainda pré-individual, é porque as forças estão sempre ligadas a uma emergência, a um processo de atualização (DELEUZE, 1983, 1996). Outro ponto importante é que uma força nunca está no singular, diz respeito sempre à sua rela- ção com outras forças. "Toda força está então em uma relação essencial com outra força. $O$ ser da força é o plural; seria propriamente absurdo pensar a força no singular" (DELEUZE, 1962 , p. 7). Na verdade, pode-se dizer que toda força é já relação, pois o que está em jogo é um poder de afetar e ser afetado.

Neste sentido que Sauvagnargues ressalta:

Trata-se menos de repudiar as formas do que delas propor uma concepção nova, como forma material e sensível, variável e intensiva, e não como forma abstrata dada. A forma sendo composta de relações de forças, não há rigorosamente senão forças, e as formas são um devir das forças (SAUVAGNARGUES, 2006, p. 69).

Estamos assim, em estreita sintonia com o pensamento de Simondon, fora do quadro que separa em termos bem definidos e opostos uma matéria rudimentar inerte e uma forma fixa que à ela se imporia. O que leva Deleuze a afirmar que o par matéria-forma deve ser substituído pelo par material-forças (DELEUZE, 2003, p. 145).

Não se trata mais de impor uma forma a uma matéria, mas de elaborar um material cada vez mais rico, cada vez mais consistente, apto a partir daí a captar forças cada vez mais intensas. O que torna o material cada vez mais rico é aquilo que faz com que os heterogêneos mantenhamse juntos sem deixar de ser heterogêneos (DELEUZE; GUATTARI, 1980, p. 406).

A captura de forças diz respeito não só a um certo modo concreto de 'funcionamento' da arte (questões relativas ao ato de criação, materialidade da obra, modos e efeitos sobre a recepção, etc), mas também a seus enlaces sutis e ao mesmo tempo vigorosos com a vida prática (reverberação sobre outros planos de atividade e práticas sociais). Na verdade, a nosso ver, estas distinções são de difícil demarcação, sendo válidas apenas à título de clareza expositiva tendo em vista que é precisamente seu 'modo de funcionamento' que 
engendra seu modo peculiar de reverberação e produção de efeitos.

Como afirma Sauvagnargues,

[...] a captura de forças abre à filosofia da arte uma via nova. Contra a hermenêutica que chapa a obra sobre o sujeito, contra a interpretação estrutural ou sociológica que encontra na obra a efetividade de estruturas objetivas, a captura de forças permite substituir a relação forma-matéria, pelo par material forças. Colocando em contato as forças heterogêneas que produzem uma captura inédita, a obra associa criador e receptor em um devir real que dá conta da mutação das culturas (SAUVAGNARGUES, 2006, p. 107).

Pensar a arte como captura de forças é retirá-la do regime das significações discursivas (e das representações mentais e privadas de um sujeito) fazendo fugir o plano sensível do regime da interpretação, para colocá-la sob o plano da experimentação sensível. A obra funciona então como um programa de experimentação. 0 desafio do artista é fazer a forma alcançar este ponto em que se vê assombrada pelas forças que nela atuam, e que seja capaz ela própria de realizar novas capturas. É essa presença das forças que responde pela expressividade da obra e por sua potência de afetação. Essas forças ressoam no espectador, tecendo-se assim um plano de movimento entre a obra e aquele que a percebe, de maneira que não se pode mais falar em termos de sujeito e objeto. Daí falarmos que uma obra nos pega ou não; pois 'conectamo-nos com ela ou não nos conectamos; construímos um plano com as nossas próprias forças e com as que emanam do objeto ou ficamos 'no exterior' (limitados à mera percepção trivial das formas) (GIL, 1996, p. 302).

Coloca-se em jogo a produção da 'sensibilidade no sensível', ou seja, a instauração de um regime de experiência sensível de outra ordem que aquela recognitiva, na qual tudo aquilo que nos comparece é imediatamente revertido em esquemas pré-definidos de ação ou interpretação. Emprestamos nosso corpo aos fluxos a-centrados e intensivos do mundo que vibram na obra. Por isso podemos dizer que a arte nos trabalha. A percepção entra em um regime de experimentação em que não se vê mais limitada a seus quadros habituais de referência, confronta-se com seus limites. Como diz Zourabichvili,

[...] o contra-senso seria pensar que a visão desencadeia a evocação: é ela ao contrário que procede ao acoplamento de um conjunto de traços objetivos e de uma imagem mental que se selecionam mutuamente. E ela se aprofunda por retornos sucessivos ao objeto, um novo aspecto do objeto sendo revelado ou passando ao primeiro plano em ressonância com uma nova camada psíquica (ZOURABICHVILI, 2004, p. 30).

A relação que se empreende então com a obra seria mal compreendida se pensada portanto como um mero acoplamento entre uma percepção objetiva e uma projeção imaginária, pois é da ordem de uma experimentação afetiva. A sensibilidade entra em um regime de metaesbilidade no qual os diferentes extratos que somos, ou que nos habitam, se acendem e se fazem presentes: vemos ao mesmo tempo com olhos de pai e de filho, de operário e vagabundo, sentimos como homem e animal, pedra e passarinho, nossos olhos se desconectam de nossas mãos, e nossas mãos vêem por si mesmas, ouvimos das palavras seu vai-e-vem e sua música, ou vemos da música o movimento das notas e dos ventos, ou ainda tudo isso ao mesmo tempo. Dá-se uma abertura às mais sutis variações e perturbações presentes no mundo.

Vemos aqui se descortinar uma dimensão ético-política fora dos quadros de uma arte engajada que visaria representar um estado de coisas ou se constituir como momento de tomada de consciência em um projeto de alguma forma emancipatório. Trata-se da constituição de um novo ethos, uma nova distribuição dos afetos e da abertura de novas 
superfícies de contato, ou nos termos de Simondon, de compatibilização sujeito-mundo.

Engendra-se uma criação de possíveis, uma nova forma de afetar e ser afetado, logo, de compor com o mundo. De compor um mundo. Por isso quando uma obra nos toca sentimos algo como um giro e ao mesmo tempo abertura, um sopro. Todos aqueles que foram em algum momento impactados por uma obra, foram já habitados por essa estranha sensação de um giro em falso, de uma iminência fulgurante e ao mesmo tempo sempre postergada de um novo universo. Sentimos como que um alargamento interior que não se preenche. A obra se constitui como um dispositivo de experimentação pois a partir de sua dimensão expressiva nos põe em contato com um plano de virtualidade que coexiste com o plano da experiência cotidiana. Ela mobiliza o plano pré-individual, ou poderíamos dizer coletivo e transindividual, que resta presente em todo sujeito, colocando em jogo o que Simondon denomina de uma operação amplificante (SIMONDON, 2005). Podemos dizer com Fellini, nessa mesma direção, que "a obra não é maravilhosa, é 'maravilhante'"' (FELLINI, 1986, p. 143).

Neste sentido, Sauvagnargues (2006) observa:

Conforme à modulação simondoniana, as relações do criador com sua obra, da obra com seu público, do artista com o corpo social, devem ser compreendidas como campos de individuação que produzem indivíduos. A obra, mas também o artista são tais indivíduos. O valor crítico da obra não se reduz mais à relação da escrita ao pensamento, nem àquela da obra à intenção. A arte se abre sobre uma via impessoal, o potencial intenso de singularidades pré-individuais qu atravessa o campo social metaestável de individuação que serve de meio à sua cristalização (SAUVAGNARGUES, 2006, p. 110).

Como marca Combes (1999), a atenção para a emergência do novo em uma sociedade e para a zona molecular-impessoal dos sujeitos constitui, é de extrema importância para se pensar a política na atualidade. Pois afirmar que a mudança social acontece pela via desse plano íntimo-comum dos sujeitos significa alargar a noção de política, para além do quadro institucional de leis ou de luta pelo poder,incluindo nesta uma dimensão nesta uma dimensão afetiva pré-individual, que é a dimensão do coletivo desubstancializado, o coletivo presente em cada um de nós: o coletivo transindividual (ESCÓSSIA, 2004).

É certo que essa experiência traz em si seus riscos, podendo ter um matiz de intolerável uma vez que é todo um sistema de referências, de pontos de orientação de ação e significação que são colocados em jogo. Como diz Deleuze, a partir de um conto de Fitzgerald, se dá uma fissura:

[...] a fissura se faz sobre esta nova linha, secreta, imperceptível, marcando um limite de diminuição de resistência, ou o aumento de um limite de exigência: não suportamos mais o que suportávamos antes, ainda ontem; a repartição dos desejos mudou em nós, nossas relações de velocidade e lentidão se modificaram, um novo tipo de angústia nos vêm, mas também uma nova serenidade (DELEUZE, 1996, p.153).

O espectador comum compartilha as aventuras insólitas dos artistas. Por meio de sua disponibilidade sensível e sua capacidade de ser afetado, estas aventuras recebem o sopro suplementar que as faz sobreviver. São seus olhos, seus ouvidos e, porque não, todo seu corpo, o campo de batalha. Estar diante de uma obra não é postar-se candidamente diante de um objeto, mas sim ceder seu peito, suas idéias, sua memória, seus afetos para serem livremente manejados, trabalhados, talvez despedaçados, unidos, enfim, transformados por tudo aquilo que habita uma página, uma tela, um palco, alto-falantes, etc. Não raro o espectador, e com ele todo um mundo, volta da aventura sem alguns de seus próprios personagens, pois ficaram pelo caminho.... 


\section{Referências}

ARNHEIM, R. A forma que procuramos. In: Para uma psicologia da arte: arte e entropia. Rio de Janeiro: Dinalivros, 1997.

ARNHEIM, R. A forma e o consumidor. In: Para uma psicologia da arte: arte e entropia. Rio de Janeiro: Dinalivros, 1997.

ARNHEIM, R. Arte e percepção visual. São Paulo: Pioneira, 1991.

ARNHEIM, R. The two faces of Gestalt psychology. American Psychologist, 41, 820 - 824, 1986.

COMBES, M. Simondon: individu et collectivité. Paris: PUF, 1999.

DELEUZE, G. Francis Bacon: lógica da sensação. Rio de Janeiro: Jorge Zahar, 2007.

DELEUZE, G. L'actuel et le virtuel. In: Dialogues. DELEUZE, G.; PARNET, C. Flammarion: Paris, 1996.

DELEUZE, G. Foucault. Paris: Les Éditions de Minuit, 1986.

DELEUZE, G. L'image-mouvement. Paris: Les Éditions de Minuit, 1983.

DELEUZE, G. Nietzsche et la philosophie. Paris: PUF, 1962.

DELEUZE, G.; GUATTARI, F. O que é a filosofia? Rio de Janeiro: Editora 34, 1992.

DEleuZE, G.; GuATTARI, F. Mille Plateaux. Paris: Les Éditions de Minuit, 1980.

ESCÓsSIA, L. M. O coletivo como plano de co-engendramento do indivíduo e da sociedade. Tese de doutorado. Programa de Pós-Graduação em Psicologia, UFRJ, 2004.

FELLINI, F. Entrevista sobre o cinema. Rio de Janeiro: Civilização Brasileira, 1986.

FERRAZ, G. C. A percepção em experimentação: uma dimensão política da experiência com a arte. Tese de doutorado. Programa de Pós-Graduação em Psicologia, UFRJ, 2010.

FERRAZ, G. C. ; KASTRUP, V. A coexistência de formas e forças: a atualidade das contribuições gestaltistas ao campo da arte. Psico (PUCRS. Impresso), v. 41, p. 424-432, 2010.

GIL, J. A imagem-nua e as pequenas percepções. Estética e metafenomenologia. Lisboa: Relógio d'Água Editores, 1996. 
GUILLAUME, P. A psicologia da forma . São Paulo: Ed. Nacional, 1966.

HAUMONT, A. L'individuation est-elle une instauration? In: Simondon. CHABOT, P. (Org.) Paris: Librairie Philosophique Vrin, 2002.

KLEE, P. Théorie de I'art moderne. Paris: Denoël, 1964.

KOFFKA, K. Princípios de psicologia da Gestalt. São Paulo: Cultrix, s/d.

KÖHLER, W. Psicologia da Gestalt. Belo Horizonte: Itatiaia, 1968.

OSTROWER, F. A sensibilidade do intelecto. Rio de Janeiro: Elsevier, 1998.

PEDROSA, M. Mundo, homem, arte em crise. São Paulo: Ed. Perspectiva, 1975.

PEDROSA, M. Da natureza afetiva da forma na obra de arte. Tese de concurso para cadeira de História da arte, Faculdade Nacional de Arquitetura, UFRJ, 1949.

PICASSO, P. Picasso speaks. In: HARRISON, C.; WOOD, P. (Org.). Art in theory: 1900-200. An anthology of changing ideas. Oxford: Blackwell Publishing, 2003.

PRIGOGINE, I. O nascimento do tempo. Lisboa: Edições 70, 1988.

SIMONDON, G. Cours sur Perception. (1964-1965). Chatou: Las éditions de la Transparence, 2006.

SIMONDON, G. L'individuation à La lumière dês notions de forme et d'information. Grenoble: Éditions Jérôme Villon, 2005.

SIMONDON, G. L'individuation psychique et collective. Paris: Editions Aubier, 1989.

ZOURABICHVILLI, F. O vocabulário de Deleuze. Rio de Janeiro: Relume Dumará, 2004.

Recebido em: 27 de maio de 2012

Aprovado para publicação em: 13 de junho de 2012

\section{Gustavo Cruz Ferraz}

Doutor em Psicologia pela Universidade Federal do Rio de Janeiro. Professor da Faculdade Salesiana Maria Auxiliadora (FSMA), Rio de Janeiro/RJ, Brasil. E-mail: gusferraz@yahoo.com.br 